\title{
Endocannabinoid system as a regulator of tumor cell malignancy - biological pathways and clinical significance
}

This article was published in the following Dove Press journal:

OncoTargets and Therapy

18 July 2016

Number of times this article has been viewed

\author{
Maria Pyszniak ${ }^{1-3}$ \\ Jacek Tabarkiewicz ${ }^{1,2}$ \\ Jarogniew J Łuszczki ${ }^{4,5}$ \\ 'Centre for Innovative Research \\ in Medical and Natural Sciences, \\ Faculty of Medicine, ${ }^{2}$ Department \\ of Immunology, Faculty of Medicine, \\ University of Rzeszów, Rzeszów, \\ ${ }^{3}$ Postgraduate School of Molecular \\ Medicine, Medical University of \\ Warsaw, Warszawa, ${ }^{4}$ Department of \\ Pathophysiology, Medical University \\ of Lublin, ${ }^{5}$ ssobolographic Analysis \\ Laboratory, Institute of Agricultural \\ Medicine, Lublin, Poland
}

\begin{abstract}
The endocannabinoid system (ECS) comprises cannabinoid receptors (CBs), endogenous cannabinoids, and enzymes responsible for their synthesis, transport, and degradation of (endo)cannabinoids. To date, two CBs, CB1 and CB2, have been characterized; however, orphan G-protein-coupled receptor GPR55 has been suggested to be the third putative CB. Several different types of cancer present abnormal expression of CBs, as well as other components of ECS, and this has been shown to correlate with the clinical outcome. Although most effects of (endo)cannabinoids are mediated through stimulation of classical CBs, they also interact with several molecules, either prosurvival or proapoptotic molecules. It should be noted that the mode of action of exogenous cannabinoids differs significantly from that of endocannabinoid and results from the studies on their activity both in vivo and in vitro could not be easily compared. This review highlights the main signaling pathways involved in the antitumor activity of cannabinoids and the influence of their activation on cancer cell biology. We also discuss changes in the expression pattern of the ECS in various cancer types that have an impact on disease progression and patient survival. A growing amount of experimental data imply possible exploitation of cannabinoids in cancer therapy.
\end{abstract}

Keywords: cannabinoids, cancer, cell signaling, cannabinoid receptor, delta-9-tetrahydrocannabinol

\section{Introduction}

Cannabinoids are active components of Cannabis sativa, which has been used for medical and recreational purposes for many years. Their activity depends mainly on activation of members of GPR family, the so-called cannabinoid receptors (CBs). ${ }^{1}$ Two subtypes of this molecule have been isolated so far - CB1 and CB2 - although a third putative $\mathrm{CB}, \mathrm{CB} 3$, has been suggested..$^{2-4}$ The main difference between them seems to be their tissue expression pattern. CB1 receptors are found mainly in the central nervous system, particularly in those regions of the brain that are involved in the control of memory (hippocampus), emotions (amygdala), motor activity (basal ganglia and cerebellum), cognition (cortex), and appetite (hypothalamus). ${ }^{5} \mathrm{CB} 1$ receptors are also present in peripheral tissues, such as uterus, testes, ovaries, and prostate. ${ }^{1,6}$ In contrast, CB2 receptors predominate in the immune system, both in cells such as lymphocytes and macrophages and in tissues such as spleen, tonsils, and lymph nodes. ${ }^{1,6}$ Recently, it has been reported that some effects of cannabinoids are non-CB1/CB2 mediated. ${ }^{7,8}$ Orphan GPR GPR55 has been suggested to be the third CB according to some reports. ${ }^{9,10}$ The expression of genes encoding a CB3 receptor has been shown in several peripheral tissues, such as spleen, tonsils, and mammae, and in endothelial
Correspondence: Maria Pyszniak Centre for Innovative Research in Medical and Natural Sciences, Faculty of Medicine, University of Rzeszów, Warzywna la, PL 35-3I0 Rzeszów, Poland

Email pyszniakmaria@gmail.com 
cells. ${ }^{8,11}$ It has been discovered only recently that cannabinoids exert an array of anticancer effects via interfering with signaling pathways involved in neoplastic transformation and tumor progression. Along with cannabinoids produced endogenously, termed endocannabinoids, and enzymes responsible for synthesis, transport, and degradation, CBs comprise the endocannabinoid system (ECS).

Among the range of endocannabinoids, two major ones are 2-arachidonoylglycerol (2-AG) and anandamide ( $N$-arachidonoylethanolamide [AEA]), both lipid-signaling molecules, containing long-chain polyunsaturated fatty acids, amides, and esters. ${ }^{1,12,13}$ Other minor compound that belongs to the "endocannabinoid family" is arachidonyl glyceryl ether named noladin. ${ }^{12,13}$ AEA originates from the phospholipid precursor, phosphatidylethanolamine, which is transformed into $N$-acylphosphatidylethanolamine (NAPE) by a calcium-dependent NAT. NAPE is subsequently converted to anandamide via four alternative enzymatic pathways; the best studied and the most direct is through catalysis by an NAPE-PLD. ${ }^{14,15}$ Similarly, 2-AG is synthesized in a twostep process. First, a phospholipase $\mathrm{C}$ enzyme catalyses the hydrolysis of inositol phospholipids to diacylglycerols, which are next transformed into 2-AG by a DAGL. ${ }^{14,15}$

Endocannabinoids are not stored in cellular vesicles but are rapidly synthesized following the increase in the intracellular calcium level. ${ }^{1,13,16}$ Released from depolarized postsynaptic neurons, endocannabinoids act as retrograde messengers, binding and activating $\mathrm{CB} 1$ receptors at presynaptic terminals. ${ }^{15-17}$ Their action results in the inhibition of neurotransmitter release, mostly glutamate and $\gamma$-aminobutyric acid. ${ }^{16}$ After activation of CBs, AEA and 2-AG undergo cellular reuptake and are degraded to arachidonic acid and ethanolamine or glycerol, respectively. ${ }^{16}$ AEA is metabolized by the enzyme FAAH, whereas 2-AG is hydrolyzed predominantly by MAGL and to a lesser extent by ABHD-6 and ABHD-12. ${ }^{18-20}$ Endocannabinoids might also be degraded through oxidation by COX, LOX, or cytochrome P450. ${ }^{15}$

Numerous studies have been performed to explain the biological role of the ECS in health and disease and its potential exploitation in therapy. ${ }^{1}$ Owing to diverse pharmacological properties, cannabinoids have attracted significant attention in recent years. In particular, they offer potential applications as antitumor drugs, based on the ability to inhibit cell proliferation and to induce tumor cell death by some members of the cannabinoid family. ${ }^{6}$ It is important to point out that the action of endocannabinoids does not match that of exogenous cannabinoids and results from research concerning their activity both in vivo and in vitro could not be easily compared.

Synthetic cannabinoids as well as plant-derived and endogenous analogs are not only oriented at activation of classical CBs but also interact with several molecules, either prosurvival or proapoptotic molecules. It has been suggested that stimulation of calcium-permeable ion channel TRPV1 or PPAR $\gamma$ and inhibition of COX-2 may mediate the proapoptotic and antiproliferative effects of anandamide and synthetic cannabinoids in cancer. ${ }^{21-23}$

A variety of mechanisms are likely to contribute to the anticancer effect of $\mathrm{CB}$ ligands. $\mathrm{CB} 1$ and/or $\mathrm{CB} 2$ receptors are coupled to several signaling pathways directly involved in cell survival, proliferation, and apoptosis, including p38 MAPK, cyclic AMP, PI3K-Akt, RhoA, JNK, EGFR, ERK, ${ }^{24}$ and ceramide pathways. ${ }^{1,19,25-30}$

Ceramide seems to be the key mediator of cannabinoidmediated anticancer effects. Cannabinoids induce sustained production of sphingolipid ceramide, which is commonly found in the cell membrane and is generated de novo by ceramide synthase or through sphingomyelin hydrolysis. ${ }^{29,31}$ Ceramide generation has been implicated in the action of cannabinoids in MG63 osteosarcoma cells, C6.9 glioma cells, and primary astrocytes through stimulation of ERK, MAPK, and/or JNK pathways. ${ }^{24,32,33}$ This effect can be mediated via $\mathrm{CB} 1$ and/or CB2 receptors. ${ }^{24,31,34}$ In addition, there are several reports describing the influence of cannabinoids on ERK cascade in cancer. Although ERK is considered as a rather proproliferative signaling molecule, ${ }^{29}$ it has been recently shown that sustained activation of ERK induces apoptosis in astrocytes. ${ }^{35}$ Regarding cannabinoid influence on the ERK activation, conflicting data have been reported, demonstrating either upregulation or reduction of this signaling pathway in response to $\mathrm{CB} 1 / \mathrm{CB} 2$ agonist. ${ }^{36,37}$

As shown earlier, mechanisms implicated in the anticancer effect of cannabinoids are quite complex; thus, in order to broaden our knowledge, further investigation of this subject is warranted.

\section{Role of cannabinoids in cancer - cultures and in vivo studies}

Currently, cannabinoids are used in the palliative therapy of cancer patients. In particular, $\Delta^{9}$-tetrahydrocannabinol (THC; Marinol), its analog nabilone (Cesamet), and Sativex $\left(\Delta^{9}\right.$-THC and cannabidiol [CBD]) were brought onto the market in several countries owing to their ability to inhibit chemo- and radiotherapy-induced side effects. ${ }^{38}$ Palliative properties of the aforementioned drugs include inhibition 
of vomiting and nausea, pain relief, stimulation of appetite, and reduction in weight loss, commonly seen in patients undergoing conventional cancer treatment. ${ }^{6,38,39}$

However, cannabinoids have been proved to affect proliferation, viability, and invasiveness of cancer cells in cultures and in vivo. ${ }^{1,6,38-40} \mathrm{~A}$ considerable body of evidence has accumulated since 1975 when Munson et $\mathrm{al}^{41}$ demonstrated for the first time the antitumorigenic action of $C$. sativa-derived cannabinoids in in vitro and in vivo experiments. For example, after 20 days of consecutive oral administration of $\Delta^{8}$-THC and cannabinol, reduction in tumor growth was seen in the Lewis lung adenocarcinoma mouse model. Antitumoral activities of CB ligands include several distinct mechanisms, such as inhibition of proliferation, induction of autophagy and apoptosis, cell-cycle arrest, reduction in metastasis outgrowth through diminishing secretion of proangiogenic molecules, and stimulation of inflammatory response against cancer. ${ }^{42-53}$ Figure 1 summarizes the influence of synthetic, plant-derived, and endogenous cannabinoids on signaling molecules, leading to tumor growth inhibition and/or cancer cell death.

\section{Influence on apoptosis and proliferation of cancer cells}

It has recently been shown that WIN 55,212-2, a synthetic nonselective $\mathrm{CB} 1 / \mathrm{CB} 2$ agonist, induces dose- and time-dependent apoptotic effects on HT29, HCT116, and Caco-2 colon cancer cells as demonstrated by loss of mitochondrial potential and activation of caspase- 3 and $-9 .^{50}$ These effects were accompanied by elevated endoplasmic reticulum (ER) stress and a subsequent increase in the level of specific markers, such as GRP78, CHOP, and TRB3. It is noteworthy that induction of GRP78 and CHOP was required for apoptosis of cancer cells and overexpression of CHOP, which were correlated with better prognosis in cancer patients. ${ }^{54-56}$ Also, upregulation of TRB3 expression was shown to be critical for inhibition of cancer cell proliferation. ${ }^{57} \mathrm{CHOP}$ and TRB3 are genes that have been demonstrated to be critically involved in cellular response to stress stimuli after THC treatment as shown by Carracedo et al..$^{58}$ They have reported THC-induced proapoptotic activity in several cancer cell lines due to generation of ceramide and upregulation of downstream target - stressregulated protein $\mathrm{p} 8$ - which subsequently mediated the increase in the expression of CHOP and TRB3. ${ }^{58}$

Contrarily, in osteosarcoma, despite the fact that WIN treatment induced ER stress markers, such as GRP78, CHOP, and TRB3, and cellular vacuolization, it did not contribute to apoptosis initiation when used alone. ${ }^{59}$ However, incubation of WIN-treated cells with TRAIL led to apoptotic death ( $~ 80 \%$ of cell viability decreased after 36 hours) as shown in morphological and biochemical hallmarks of apoptosis and concomitant translocation of GRP78 to cell surface and upregulation of tumor suppressor factor PAR-4. ${ }^{59}$ In human gastric cancer cells, WIN was able to arrest the cell cycle in the $\mathrm{G} 0 / \mathrm{G} 1$ phase, thus reducing proliferation and inducing apoptosis, and both these effects were mediated via downregulation of pAkt. ${ }^{49,53}$

Interestingly, WIN-induced killing of colon cancer cells depends upon the downregulation of PPAR $\gamma$, at both mRNA and protein levels. Indeed, pharmacological or genetic inhibition of PPAR $\gamma$ exerted similar effect to WIN, inducing cell death and moreover in combination with WIN treatment, even potentiated this effect. ${ }^{50}$ This observation is somewhat unexpected, since the majority of reports show that cannabinoid-induced apoptosis relies on upregulation of PPAR $\gamma$ expression and this effect could be attenuated by either genetic ablation or pharmacological inhibition of the PPAR $\gamma$ pathway. ${ }^{23,60}$ On the other hand, AEA-induced apoptosis in tumorigenic JWF2 keratinocytes depends upon activation of COX-2, which then induces ER stress. ${ }^{52}$ Furthermore, it was determined that COX-2 metabolizes AEA to $\mathrm{J}$-series prostaglandins and this mechanism is required for ER stress-associated apoptotic process activated by AEA.${ }^{52}$ Cannabinoid-induced apoptosis may be, actually, paralleled by both PPAR $\gamma$ and COX-2 upregulation. ${ }^{61}$

In $\mathrm{LNCaP}$ prostate carcinoma cells, $\mathrm{CBD}$ significantly reduced viability and induced apoptosis, which was partly due to antagonism of TRPM8 and was accompanied by diminished expression of androgen receptor, p53 activation, and elevated levels of reactive oxygen species (ROS). ${ }^{62}$ The proapoptotic effect of CBD was confirmed by upregulation of PUMA and CHOP, markers of apoptotic intrinsic pathways, and elevated intracellular $\mathrm{Ca}^{2+}$ levels. ${ }^{62}$ In colon cancer cell lines, inhibition of proliferation induced by $\mathrm{CBD}$ has been demonstrated, and this effect was CB1, TRPV1, and/or PPAR $\gamma$ dependent. ${ }^{62}$ Likewise, standardized $C$. sativa extracts (CBD botanical drug substance [BDS]) with high content of CBD were shown to be effective in decreasing proliferation of cancer cells as shown by Romano et al. ${ }^{63}$

Anticancer activity of some synthetic compounds has also been indicated in research. In a study by Ortega et al, CP55-940, a CB agonist, was the most effective agent to induce antitumor action in C6 (rat) and U373 (human) glioma tumor lines over synthetic cannabinoid WIN 55,212-2 and the endogenous agonist AEA. ${ }^{64}$ Moreover, this study proposes apoptosis as a major mechanism contributing 


\begin{tabular}{|c|c|c|}
\hline \multicolumn{3}{|c|}{ Apoptosis } \\
\hline Mediator & Effect & Reference \\
\hline WIN-55,212-2 & $\begin{array}{l}\downarrow \Delta \Psi \mathrm{m}, \uparrow \text { caspase-3, } \\
\uparrow \mathrm{GRP78}, \uparrow \mathrm{CHOP}, \\
\uparrow \mathrm{TRB} 3\end{array}$ & 50 \\
\hline AEA & $\uparrow$ ER stress & 52 \\
\hline WIN-55,212-2 & $\downarrow$ pAkt & 53 \\
\hline THC & $\begin{array}{l}\uparrow \text { ceramide, } \uparrow p 8, \\
\uparrow \text { ER stress, } \uparrow \mathrm{CHOP}, \\
\uparrow \text { TRB3 }\end{array}$ & 58 \\
\hline $\begin{array}{l}\text { WIN-55,212-2 + } \\
\text { TRAIL }\end{array}$ & $\uparrow$ PAR-4 & 59 \\
\hline CBD & $\begin{array}{l}\downarrow \text { PUMA, } \uparrow \text { CHOP, } \\
\downarrow \text { TRPM8, } \\
\uparrow \text { intracellular } \mathrm{Ca}^{2+}, \\
\text { activation of } p 53, \uparrow \text { ROS, } \\
\downarrow \text { AR } \\
\end{array}$ & 62 \\
\hline O-1602 & $\uparrow \mathrm{BAX}, \uparrow \mathrm{p} 53$ & 65 \\
\hline $\begin{array}{l}\text { Met-F-AEA + } \\
\text { URB597 }\end{array}$ & $\begin{array}{l}\downarrow \text { pro-caspase } 9, \\
\downarrow \text { pro-PARP }\end{array}$ & 75 \\
\hline
\end{tabular}

\begin{tabular}{|c|c|c|}
\hline \multicolumn{3}{|c|}{ Neovascularization and angiogenesis } \\
\hline Mediator & Effect & Reference \\
\hline $\begin{array}{l}\text { WIN-55,212-2, } \\
\text { JWH-133 }\end{array}$ & $\begin{array}{l}\downarrow \text { VEGF, } \downarrow \text { PIGF, } \\
\downarrow \text { Ang2, } \downarrow \text { EGF-R }\end{array}$ & 44 \\
\hline $\begin{array}{l}\text { WIN-55,212-2, } \\
\text { JWH-133 }\end{array}$ & $\downarrow$ VEGF, $\downarrow$ VEGFR2 & 43 \\
\hline CBD & $\begin{array}{l}\downarrow \text { MMP-2, } \downarrow \text { MMP-9, } \\
\downarrow \text { TIMP1, } \\
\downarrow \text { SERPINE1/PAI1, } \\
\downarrow \text { UPA, } \downarrow \text { CXCL16, } \\
\downarrow \text { IL-8, } \downarrow \text { ET-1, } \\
\downarrow \text { PDGF-AA }\end{array}$ & 94 \\
\hline Met-F-AEA & $\downarrow$ MMP-2 & 93 \\
\hline
\end{tabular}

\begin{tabular}{|c|c|c|}
\hline \multicolumn{3}{|c|}{ Proliferation } \\
\hline Mediator & Effect & Reference \\
\hline WIN-55,212-2 & $\downarrow$ pAkt & 53 \\
\hline WIN-55,212-2 & $\begin{array}{l}\downarrow \text { pAkt, } \uparrow \text { p-ErRK1/2, } \downarrow \text { pAkt, } \\
\uparrow \text { Kip1/p27, } \uparrow \text { Cip } 1 / \text { WAF } 1 / \text { p21, } \\
\downarrow \text { cyclin D1, } \downarrow \text { cyclin E, } \downarrow \text { Cdk } 2, \\
\downarrow \text { Cdk } 4, \downarrow \text { Cdk } 6, \downarrow \text { phospho-Rb, } \\
\downarrow \text { E2F-1 }\end{array}$ & 49 \\
\hline CBD & $\begin{array}{l}\downarrow \text { NF-kB translocation, } \\
\downarrow \text { pEGFR, } \downarrow \text { p-ERK, } \downarrow \text { pAkt }\end{array}$ & 47 \\
\hline WIN-55,212-2 & $\uparrow \mathrm{GRP} 78, \uparrow \mathrm{CHOP}, \uparrow$ TRB3 & 59 \\
\hline O-1602 & $\begin{array}{l}\downarrow \text { PCNA, } \downarrow \text { STAT3, } \\
\downarrow p-N F \text { B p65, } \downarrow \text { TNF } \alpha\end{array}$ & 65 \\
\hline $\begin{array}{l}\text { Met-F-AEA + } \\
\text { URB597 }\end{array}$ & $\begin{array}{l}\downarrow \text { p-EGFR }, \downarrow \text { p-ERK, } \downarrow \text { p-Akt } \\
\downarrow \text { cyclin D1 } \downarrow \text { CDK1 }\end{array}$ & 75 \\
\hline Met-F-AEA & $\downarrow p-E R K$ & 93 \\
\hline
\end{tabular}

\begin{tabular}{|l|l|c|}
\hline \multicolumn{3}{|c|}{ Metastasis formation } \\
\hline \multicolumn{1}{|c|}{ Mediator } & \multicolumn{1}{|c|}{ Effect } & Reference \\
\hline WIN-55,212-2 & $\downarrow$ MMP-2, $\downarrow$ VEGF-A & 53 \\
\hline CBD & $\downarrow$ MMP-2, $\downarrow$ MMP-9 & 47 \\
\hline $\begin{array}{l}\text { Met-F-AEA + } \\
\text { URB597 }\end{array}$ & $\downarrow$ MMP-2 & 75 \\
\hline CBD, O-1663 & $\downarrow$ Id1 & 84 \\
\hline THC & $\downarrow$ MMP-2 & 34 \\
\hline AM404 & $\begin{array}{l}\downarrow \text { NFAT, } \downarrow \text { NF-KB, } \downarrow \text { MMP-1, } \\
\text { MMP-3, } \downarrow \text { MMP-7 }\end{array}$ & 92 \\
\hline $\begin{array}{l}\text { CBD, } \Delta 9 \text {-THC, MA, } \\
\text { JWH-133 }\end{array}$ & $\uparrow$ ICAM-1, $\uparrow$ TIMP-1 & 96 \\
\hline$\Delta 9-T H C, M A$ & $\uparrow$ TIMP-1 & 98 \\
\hline CBD & $\uparrow$ ICAM-1, $\uparrow$ TIMP-1 & 103 \\
\hline
\end{tabular}

\begin{tabular}{|c|c|c|}
\hline \multicolumn{3}{|c|}{ Autophagy } \\
\hline Mediator & Effect & Reference \\
\hline $\begin{array}{l}\text { ACPA + GEM, } \\
\text { GW405833+ GEM, } \\
\text { SR141716+ GEM }\end{array}$ & $\begin{array}{l}\uparrow \mathrm{ROS}, \uparrow \mathrm{XBP}-1, \uparrow \mathrm{Grp} 78, \\
\uparrow \mathrm{CHOP}\end{array}$ & 46 \\
\hline ACPA, GW405833 & $\begin{array}{l}\uparrow \text { ROS, } \uparrow \text { AMP/ATP ratio, } \\
\uparrow \text { AMPK }, \downarrow \text { mTORC } 1, \\
\downarrow \text { HIF- } 1 \alpha, \downarrow \text { PDHK, } \\
\downarrow \text { GAPDH }, \downarrow \text { Akt, } \downarrow \text { c-Myc }\end{array}$ & 45 \\
\hline$\Delta 9-\mathrm{THC}$ & $\begin{array}{l}\text { Ceramide accumulation, } \\
\uparrow \text { elF2 } \alpha, \downarrow \text { ER stress, } \\
\uparrow \text { p8/TRB3, } \\
\downarrow \text { Akt/mTORC1 }\end{array}$ & 51 \\
\hline WIN-55,212-2 & $\uparrow$ LC3-II, $\downarrow$ p-Akt & 50 \\
\hline$\Delta 9-\mathrm{THC}, \mathrm{JWH}-015$ & $\begin{array}{l}\uparrow \text { p8/TRB3, } \uparrow \text { LC3-II, } \\
\downarrow \text { Akt/mTORC } 1, \downarrow p-S 6, \\
\uparrow \text { AMPK }\end{array}$ & 80 \\
\hline O-1663 & $\uparrow$ LC3-II & 84 \\
\hline
\end{tabular}

Figure I Influence of synthetic, plant-derived, and endogenous cannabinoids on signaling molecules leading to tumor growth inhibition and/or cancer cell death.

Notes: $\uparrow$, increased; $\downarrow$, decreased.

Abbreviations: ER, endoplasmic reticulum; ROS, reactive oxygen species; AMPK, 5'AMP-activated protein kinase; Ang, Angiopoietin; AEA, N-arachidonoylethanolamide; CBD, Cannabidiol; CXCL, Chemokine (c-x-c motif) ligand; EGFR, Epidermal growth factor receptor; ERK, Extracellular signal-regulated kinase; GAPDH, Glyceraldehyde 3-phosphate dehydrogenase GEM, Gemcitabine; GRP, Glucose-regulated protein; Met-F-AEA, 2-methyl-20-F-anandamide; MMP, Matrix metalloproteinases; NF-אB, nuclear factor kappa-light-chain-enhancer of activated B cells; PCNA, Proliferating cell nuclear antigen; STAT, Signal transducer and activator of transcription; TIMP, Tissue inhibitor matrix metalloproteinases; THC, Tetrahydrocannabinol; TRB, Tribblespseudokinase; TRPM, Transient receptor potential cation channel subfamily M member; uPA, Urokinase-type plasminogen activator; VEGF, Vascular endothelial growth factor; VEGFR, Vascular endothelial growth factor receptor.

to cannabinoid-induced death of cancer cells, at least for CP55-940. ${ }^{64}$ The atypical cannabinoid O-1602 inhibited cancer cell proliferation and induced apoptosis in two colon cancer cell lines, HT-29 and SW480, ${ }^{65}$ and reduced viability of melanoma cells via GPR55 activation. ${ }^{66}$ In addition, antineoplastic effect was accompanied by decreased level of proliferation marker PCNA and depression of oncogenic transcription factors NF- $\kappa \mathrm{B}$ and STAT3 and protumorigenic cytokine TNF, while proapoptotic molecules BAX and p53 increased. ${ }^{65}$ This is noteworthy, since TNF has 
been previously shown to promote cancer cell motility and invasiveness, which is attributed to activation of NF- $\mathrm{KB}$ signaling. ${ }^{67}$ In addition, TNF may contribute to mutations in tumor supressor genes, such as p53. ${ }^{65}$

In human bladder carcinoma (ECV304), dramatic, time-related decline in proliferation of cells was obtained in response to an inverse agonist of CB1 receptor, AM281. As the authors suggested, delay in progression of each cellcycle phase, rather than growth inhibition, underlies the antiproliferative effect of AM281. ${ }^{48}$ It has been shown that radiation combined with WIN treatment induced a growthinhibitory effect, without causing death of breast cancer cells. ${ }^{68}$ Furthermore, antiproliferative effects of combination of WIN and radiation therapy were more effective than use of either agent separately. ${ }^{68}$

The EGFR is a cell surface receptor tyrosine kinase, in which activation increases tumor growth, cellular differentiation, and migration and inhibits apoptosis. ${ }^{69-71}$ Overexpression of EGFR is found in diverse cancer types and is often associated with poor prognosis. ${ }^{69,72}$ Some authors suggest that EGFR expression may serve as a negative prognostic factor. ${ }^{72,73} \mathrm{Sev}-$ eral lines of evidence have shown antiproliferative activity of (endo)cannabinoids due to downregulation of EGFR signaling route, although, in contrast, Fiori et $\mathrm{al}^{74}$ reported an enhanced expression of EGFR in AM251-treated cells (CB1 inverse agonist). Synthetic and natural cannabinoids (2-methyl-20F-anandamide [Met-F-AEA] and CBD) inhibit EGF-induced proliferation and chemotaxis of different types of cancer cells, which is related to decreased expression of EGFR and its downstream targets Akt, ERK, and NF- $\mathrm{KB}$ signaling. ${ }^{47,75} \mathrm{In}$ non-small cell lung cancer and human cutaneous melanoma, inhibition of AEA-degrading enzyme (FAAH) with URB597 potentiated antitumorigenic effect of AEA and its analog MetF-AEA ${ }^{66,75}$ Also, inhibition of 2-AG hydrolysis with the use of MAGL inhibitor, JZL184, produced an antiproliferative effect in EGF-treated prostate cancer cells. ${ }^{76}$

Antiproliferative and proapoptotic activities of several cannabinoids have also been proved in preclinical studies. Aviello et $\mathrm{a}^{42}$ demonstrated chemopreventive effect of nonpsychotropic CBD in colon carcinoma-bearing mice treated with azoxymethane (AOM). CBD reduced preneoplastic lesion and tumor formation induced by $\mathrm{AOM}$ and counteracted the upregulation of pAkt. ${ }^{42}$ Indeed, in colorectal cancer, CBD BDS significantly reduced the formation of AOM-induced aberrant crypt foci and polyps, as well as growth of xenograft tumor obtained by injection into nude mice. ${ }^{63}$ A similar result was observed in prostate cancer, where CBD BDS reduced the size of xenografts generated from $\mathrm{LNCaP}$ cells. ${ }^{62}$
Anticancer activity of some synthetic compounds has also been indicated in research. Treatment with the atypical cannabinoid - O-1602 - led to $>30 \%$ reduction in tumor incidence and $>50 \%$ decrease in tumor volume. ${ }^{65}$ Further investigation revealed that these effects were associated with antiproliferative and proapoptotic activities of cannabinoids as shown by alterations in PCNA (decreased) and proapoptotic markers, such as BAX and p53, (increased) levels. ${ }^{65}$

A combination treatment with the use of the synthetic compound Met-F-AEA and FAAH inhibitor URB597 resulted in inhibition of EGF signaling cascade in xenograftbearing mice, leading to reduced tumor growth. ${ }^{75}$ Additionally, the use of Met-F-AEA combined with URB597 was shown to induce superior therapeutic response when compared to each substance alone..$^{75}$

\section{Induction of autophagy}

Recently, autophagy has drawn an increasing interest due to its dual role, depending on a cellular context and strength and duration of stimulating signal. ${ }^{77,78}$ In regard to cancer, it has been demonstrated that autophagy may either promote survival or induce cell death in the process termed programmed cell death type II. ${ }^{78}$ In HT29 colon cancer cells, WIN treatment triggered an autophagic process, as shown by accumulation of $\mathrm{p} 62$ and LC3; however, prolonged incubation with WIN blocked an autophagic flux after autophagosome formation. Apparently, although autophagy has been implicated in the proapoptotic effect of several cannabinoids, in this case, WIN-induced death of colon cancer cells and autophagy seemed to play a prosurvival role. ${ }^{45,50,77,79}$

In contrast, Donadelli et al ${ }^{46}$ reported that gemcitabine (GEM) in combination with synthetic cannabinoids (arachidonoylcyclopropamide, GW405833, or SR141716) induced synergistic reduction in pancreatic adenocarcinoma cell growth by ROS-dependent autophagic cell death in an in vitro experiment. Importantly, combinations of GEM and cannabinoids exerted greater efficacy in cell growth inhibition in GEMresistant cell lines compared to GEM-sensitive ones, depending on the increase in intracellular ROS. ${ }^{46}$ Since pancreatic cell lines have been shown to be more resistant to GEM due to lower basal levels of ROS, the combination therapy utilizing cannabinoids may help to overcome GEM resistance at least in pancreatic cancer cells. ${ }^{79}$ It has been further evaluated that cannabinoidinduced autophagy is closely related to an increased AMP/ATP ratio and subsequent activation of AMPK in Panc1 cells. ${ }^{45}$

There is evidence for cross talk between autophagy and apoptosis, and factors characteristic of the latter (GRP78, CHOP, TRB3) might also play a crucial role in the autophagic process. ${ }^{46,59,80,81}$ Moreover, autophagy is often suggested to 
precede apoptosis and some autophagy-related molecules may facilitate apoptosis induction. ${ }^{49,82}$ In an in vitro study on human glioma cells, $\Delta^{9}$-THC evoked cancer cell death through the induction of autophagy, which was associated with accumulation of ceramide de novo and phosphorylation of eIF $2 \alpha$, a protein related to ER stress response..$^{51,83}$ THC and/or JWH-015 were shown to upregulate p8/TRB3 cascade, which further led to decreased phosphorylation of prosurvival Akt kinase and inhibition of Akt/mTORC1 axis in glioma and hepatocellular carcinoma (HCC) cells. ${ }^{51,80}$ The authors proposed that the latter is crucial for cannabinoidinduced autophagy of cancer cells. ${ }^{51}$ In breast cancer cells, O-1663, a THC and CBD analog, was reported to stimulate autophagy, as shown in LC3-II accumulation, and was even more active in inducing apoptosis than THC. ${ }^{84}$

Unfortunately, our knowledge about the cannabinoidinduced autophagy of cancer cells in vivo is still scarce. In fact, it has been demonstrated only in a few animal cancer models. Treatment of mice bearing BRAF wild-type melanoma xenografts with the use of Sativex-like preparation (a mixture of equal doses of THC and CBD) induced substantial decrease in melanoma viability and tumor growth, paralleled by an activation of the autophagic process. ${ }^{85}$

Similarly, THC administered intraperitoneally to U87MG xenograft-bearing mice produced decrease in tumor growth via the induction of autophagy. ${ }^{51}$ Regarding clinical research, analysis of tumors of two patients with recurrent glioblastoma multiforme demonstrated features of autophagic phenotype after the intracranial inoculation of THC. ${ }^{51}$ No side effects were observed in clinical trial patients or in tumor-bearing mice. ${ }^{51}$

\section{Impact on metastasis formation}

Cannabinoids are thought to modulate secretion of several proteins, leading to decrease in metastasis formation. Matrix metalloproteinases (MMPs) have long been associated with extracellular matrix degradation, the process intimately involved in the premetastatic niche development. ${ }^{86}$ In particular, activation of TGF- $\beta$ by MMP-2, MMP-9, and MMP-14 favors invasion of tumor cells and promotes metastasis outgrowth. ${ }^{87}$ Overexpression of MMPs has been shown in various cancer types, and it had an unfavorable impact on patients' survival. ${ }^{34,88-91}$ The downregulation of MMP by cannabinoids has been demonstrated in several types of neoplasm. ${ }^{53,92-94}$ Solinas et al ${ }^{94}$ showed a concentrationdependent decrease in proliferation and migration of human umbilical vein endothelial cells (HUVECs) after incubation with $\mathrm{CBD}$, an effect associated with downregulation of several angiogenesis-related proteins, particularly MMP-2 and MMP-9, and also TIMP-1, SERPINE1/PAI1, uPA, CXCL16, IL-8, ET-1, and PDGF-AA. In gastric cancer, WIN 55,212-2 treatment produced dose-dependent decrease in the expression of VEGF-A and MMP-2, but not in the levels of MMP-7 and MMP-9 proteins. ${ }^{53}$

The metabolically stable anandamide analog Met-F-AEA was effective in inhibiting endothelial cells sprouting, and it was partly due to diminished MMP-2 secretion after treatment with Met-F-AEA. ${ }^{93}$ Of note, exposition of HUVECs to SR141716, a CB1 antagonist, reversed the inhibitory effect of Met-F-AEA, confirming its dependency on activation of CB1 receptor. ${ }^{93}$ In neuroblastoma cells, $N$-arachidonoylphenolamine (AM404), a paracetamol lipid metabolite, inhibited transcription factors NFAT and NF- $\mathrm{KB}$, which resulted in decreased levels of MMP-1, MMP-3, and MMP-7 and subsequent inhibition in cell migration and invasion..$^{92}$ Despite the fact that AM404 is known as a dual agonist of CB1 and TRPV1, its antimigratory activity was evoked independently of CB1 and TRPV1 binding. ${ }^{92}$

Recently, ICAM-1 and its downstream target TIMP-1 were proposed to play a pivotal role in inhibiting carcinoma invasion and metastasis. ${ }^{95-98}$ Increased levels of ICAM-1 reduce the rate of tumor growth, and an inverse correlation between ICAM-1 expression and metastasis incidence was noted in several oncologic disorders. ${ }^{99-101}$ In line with this notion, there are data showing antimigratory and antiangiogenic activities of cannabinoid, accompanied by the upregulation of both ICAM-1 and TIMP-1..$^{96-98}$ Ramer et al ${ }^{96}$ observed that CBD, $\Delta^{9}$-THC, and $\mathrm{R}(+)$-methanandamide or JWH-133, a CB2 agonist, decreased migration and sprout formation of HUVECs suspended in conditioned media of A549 lung cancer cells. The same group of researchers also found time- and dose-dependent suppression of human cervical cancer (HeLa) cell invasion induced by methanandamide and THC. ${ }^{98}$ In both cases, observed phenomena were accompanied by increased expression of TIMP-1 and ICAM-1 molecules. ${ }^{96,98}$

In A549 and H460 lung cancer cell lines, CBD-induced upregulation of ICAM-1 enhanced susceptibility of tumor cells to adhesion of lymphokine-activated killer (LAK) cells and LAK cell-mediated cytotoxicity. Both effects were reversed by pharmacological or genetic blocking of ICAM-1 or by using antagonists of CB1, CB2, or TRPV1. ${ }^{102}$ Also adhesion molecules, such as P- and E-selectins, exhibit increased surface exposure on cancer cells in response to cannabinoids, which is related to enhanced recruitment of immune cells to the tumor microenvironment. ${ }^{48,103}$ Coupling to CB1 and $\mathrm{CB} 2$ receptors, 2-AG triggered an immune response against 
bladder carcinoma cells through increased secretion of P- and E-selectins and enhanced TNF release by these cells and subsequent adhesion of Jurkat T lymphocytes. ${ }^{48}$

Cannabinoids have shown antimetastatic effects in in vivo cancer models. A strong correlation between metastatic capacity of cancer cells and the expression of transcriptional regulator Id1 was suggested in research. ${ }^{104} \mathrm{Id} 1$ is considered as a tumor promoter and has been previously reported to induce formation of breast cancer metastasis. ${ }^{105,106}$ In one study, $\mathrm{CBD}$, a natural component of $C$. sativa, reduced metastasis in advanced stages of breast cancer in vivo, mainly through the downregulation of transcriptional regulator Id1 and upregulation of $\operatorname{ROS}^{84}$ Further investigation revealed that O-1663, a derivative of CBD and agonist of the CB2 receptor, is even more potent than its parent compound in inhibiting total metastasis in human MDA-MB231 and mouse 4T1 models of breast cancer metastasis. Furthermore, O-1663 appeared to be efficacious in prolonging survival in both tested preclinical models. ${ }^{84}$

It is already well known that neovascularization and angiogenesis play a prominent role in metastasis formation in tumors and contribute to tumor progression. ${ }^{107}$ Strong migratory potential is attributed to invasive carcinoma cells, which additionally produce angiogenic factors, like VEGF, a key regulator of new blood vessels growth. ${ }^{107,108}$ VEGF has a major impact on tumor development, mainly through coupling and activating the tyrosine kinase receptor VEGFR2. ${ }^{109}$ Accumulating evidence demonstrated antimigratory and antiangiogenic properties of plant-derived cannabinoids and cannabinoid-based drugs, although proangiogenic activity of some endocannabinoids has also been observed. ${ }^{110}$

Local administration of WIN 55,212-2 (CB1/CB2 agonist) or JWH-133 (CB2 agonist) resulted in considerable inhibition of tumor growth in a mouse model of skin tumor. This was accompanied by decrease in the size of blood vessels and decreased secretion of proangiogenic factor VEGF, placental growth factor, and angiopoietin 2, indicating impairment of vascularization. ${ }^{44}$ As shown in mouse gliomas, cannabinoid treatment (WIN 55,212-2 or JWH-133) lowered VEGF pathway, and similar results were observed in two patients with glioblastoma multiforme. ${ }^{43}$ Similarly, CBD inhibited VEGF-induced formation of capillary-like structures from HUVECs in the in vivo Matrigel sponge angiogenesis assay. ${ }^{94}$ In this experiment, antiangiogenic properties of $\mathrm{CBD}$ were demonstrated in decreased hemoglobin content of pellets obtained from C57/BL6 male mice. ${ }^{94}$ Similarly, Met-F-AEA exhibited an antiangiogenic effect, inducing a twofold or eightfold reduction in the number of new capillaries, shown in the in vivo CAM assay. ${ }^{93}$

The ability to modulate the tumor microenvironment by cannabinoids was also confirmed in animal cancer models. In the case of breast cancer, Elbaz et $\mathrm{al}^{47}$ reported significantly decreased recruitment of tumor-associated macrophages, especially protumorigenic M2 type, to primary tumor and secondary tumor metastatic sites after the peritumoral administration of CBD. The authors suggested that CBD affects the cytokine secretion profile of cancer cells, which was further confirmed by lowered levels of CCL3 and GM-CSF, molecules implicated in the stimulation of macrophage chemotactic activity and formation of metastasis in various tumor types. ${ }^{47,111-113}$

\section{Expression of CBs and its prognostic value}

To date, CBs have been detected in many cancer types and are proposed to be potential therapeutic agents due to their involvement in controlling survival and death of cells. ${ }^{40,114,115}$ Several studies have shown that the components of ECS present diverse expression in cancer, although the level and direction of this diversity are not always the same. ${ }^{116-119}$ Interestingly, $\mathrm{CBs}$ have been reported to be overexpressed in malignant cells of many cancer types compared to their nontransformed counterparts. Apparently, a lowered expression of $\mathrm{CB}$ in normal cells appears to be a protection mechanism from the proapoptotic and antiproliferative effects of some $\mathrm{CB}$ receptor ligands. It is hypothesized that increased $\mathrm{CB}$ expression may be associated with some features of cancer aggressiveness (Table 1).

The ECS has been studied most extensively in case of prostate cancer and central nervous system tumors. Sánchez et al ${ }^{120}$ examined biopsies from human astrocytoma and reported that $70 \%$ of them expressed elevated levels of CB1 and CB2 and upregulated CB2 was directly related to tumor malignancy. Data presented by Ellert-Miklaszewska et al showing increased CB2 receptor in higher histologic grade of glioblastoma were in line with these results. ${ }^{12}$ Some data present an opposite expression of both CBs in glial cancers where significantly lower $\mathrm{CB} 1$ and greater $\mathrm{CB} 2$ immunoreactivities were seen in the membranes of glioblastoma multiforme in comparison to normal postmortem brain tissue. ${ }^{122}$ In this case, the authors speculate whether an increased expression of CB2 might be related to an increase in macrophages invading brain tumor. ${ }^{122}$

Regarding prostate malignancy, elevated levels of $\mathrm{CB} 1$ and $\mathrm{CB} 2$ expression were reported in CA-human 
Table I CB expression in human tumors and its clinical relevance

\begin{tabular}{|c|c|c|c|c|}
\hline Number & Receptor expression & Tumor & Influence & References \\
\hline 1 & $\uparrow \mathrm{CBI}$ & Prostate cancer (stage IV) & $\begin{array}{l}\uparrow \text { Gleason score, } \uparrow \text { incidence of metastases at diagnosis, } \\
\uparrow \text { tumor size, } \uparrow \text { rate of proliferation, } \downarrow \text { disease-specific survival }\end{array}$ & 40 \\
\hline 2 & $\uparrow \mathrm{CBI}, \uparrow \mathrm{CB} 2$ & $\mathrm{HCC}$ & $\uparrow$ disease-free survival & 115 \\
\hline 3 & $\uparrow \mathrm{CB} 2$ & Colorectal cancer & $\downarrow$ disease-free survival, $\downarrow$ overall survival, $\uparrow$ tumor growth & 118 \\
\hline 4 & $\uparrow \mathrm{CB} 2$ & Astrocytoma & $\uparrow$ tumor malignancy & 120 \\
\hline 5 & $\uparrow \mathrm{CB} 2$ & Glioblastoma & $\uparrow$ histologic grade & 121 \\
\hline 6 & $\uparrow \mathrm{CBI}$ & Prostate cancer & $\begin{array}{l}\uparrow \text { Gleason score, } \uparrow \text { incidence of metastases at diagnosis, } \\
\uparrow \text { tumor stage, } \uparrow \text { Ki67 index }\end{array}$ & 123 \\
\hline 7 & $\uparrow \mathrm{CBI}$ & Colorectal cancer & $\downarrow$ disease outcome & 124 \\
\hline 8 & $\uparrow \mathrm{CBI}$ & Colorectal cancer (stage II MSS) & $\downarrow$ disease-specific survival & 125 \\
\hline 9 & $\uparrow \mathrm{CB} 2$ & $\begin{array}{l}\text { Head and neck squamous cell } \\
\text { carcinoma }\end{array}$ & $\downarrow$ disease-specific survival & 128 \\
\hline 10 & $\uparrow \mathrm{CB} 2$ & Glioma & $\uparrow$ tumor malignancy & 130 \\
\hline 11 & $\downarrow \mathrm{CBI}$ & PDAC & $\downarrow$ survival & 146 \\
\hline
\end{tabular}

Notes: $\uparrow$, increased; $\downarrow$, decreased.

Abbreviations: CB, cannabinoid receptor; HCC, hepatocellular carcinoma; MSS, microsatellite stable; PDAC, pancreatic ductal carcinoma.

papillomavirus-10 (virally transformed cells derived from adenocarcinoma of human prostate tissue) and other human prostate cancer cell lines (LNCaP, DU145, PC-3, CWR22Rv1) than in normal prostate epithelial cells and PZ-HPV-7 (virally transformed cells derived from normal human prostate tissue) cells. ${ }^{114}$ Similar results were obtained in other studies on prostate carcinoma where upregulated expression of CB1 and/or CB2 receptors was detected in cancer cells compared to their nonmalignant counterparts. ${ }^{40,123}$ With regard to prognosis, a high expression of CB1 in prostate tumor tissue, but not in normal tissue, is correlated with a higher Gleason score and presence of metastases at diagnosis. ${ }^{123}$ After a long follow-up period, it has been shown that patients with prostate carcinoma had significantly shorter disease-specific survival when malignant epithelial cells expressed a high CB1-immunoreactivity (CB1-IR) score. ${ }^{40}$ This finding indicates association between $\mathrm{CB} 1$ and disease severity and outcome. ${ }^{39}$ Likewise, high CB1-IR is an indicator of a poorer prognosis for patients (following surgery) in stage IV colorectal cancer as well as in stage II microsatellite stable colorectal cancer, which additionally is associated with shorter survival. ${ }^{124,125}$

In human HCC, in situ hybridization analysis revealed overexpression of mRNAs for CB1 and CB2 in HCC samples (62\% and 53\%, respectively) ${ }^{115}$ Similarly, immunohistochemical analysis showed high expression of CB1 in 29 (45\%) and CB2 in 33 (52\%) of 64 HCC samples. In contrast to aforementioned studies, further evaluation indicated significantly longer disease-free survival time in $\mathrm{HCC}$ patients with higher $\mathrm{CB} 1$ and $\mathrm{CB} 2$ expression, implying usefulness of $\mathrm{CB}$ expression as a positive prognosis indicator in cancer. ${ }^{115}$ Such divergent results indicate that $\mathrm{CB}$ receptor expression and its prognostic value in human neoplasms depend strongly on the cancer type.
In addition to $\mathrm{CB} 1$ expression, high levels of other cannabinoid-like molecules and signaling pathways interacting with ECS have been shown in several types of malignancy. ${ }^{66,126,127}$ The data are shown in Table 2. Members of the GPRs family, in particular, GPR55, GPR119, and GPR18, were found in hCMEC/D3 human brain endothelial cells and A2058 melanoma cells. ${ }^{127}$ These findings were further supported by the results of two other reports. There was found a predominant expression of CB1 in Hodgkin-ReedSternberg cells of classical Hodgkin's lymphoma, whereas the surrounding, reactive nontumor lymphatic infiltrate was negative. ${ }^{126}$ In the same study, GPR55 was strongly expressed in Hodgkin's lymphoma and non-Hodgkin's lymphoma cell lines. In melanoma cell line A375, not only CB1 and GPR55 but also TRPV1 and COX-2 receptors were highly expressed. ${ }^{66}$ TRPV1 correlates with the degree of malignancy, as shown in PCC epithelial tissues, where elevated levels of CB1 and TRPV1 were observed. ${ }^{123}$

A strong expression of the $\mathrm{CB} 2$ receptor may contribute to poor prognosis in cancer patients as shown in primary squamous cell carcinoma of the head and neck. ${ }^{128}$ It is most probably due to immunosuppressive properties of (endo) cannabinoids mediated via the CB2 receptor. In fact, it has been reported that THC administration to lung cancerbearing mice induced accelerated growth of tumor implant, mainly due to the augmentation of IL-10 and TGF- $\beta$ and downregulation of IFN- $\gamma$ release, indicating reduction in host immune response. ${ }^{129}$ Furthermore, both T lymphocytes and antigen-presenting cells had impaired capability to generate alloreactivity against tumor. ${ }^{129}$

Recently, augmented levels of CB1 and CB2 were observed in glioma tissue, and further analysis revealed a 
Table 2 The expression of the cannabinoid-like molecules and enzymes responsible for (endo)cannabinoid metabolism

\begin{tabular}{llll}
\hline Group & Molecule & Primary cancer type/cancer cell line & References \\
\hline GPRs & GPR55 & HL: L428, L540, LI236, HDLM2, and KM-H2 & I26 \\
& & NHL: Karpas 422, BJAB, SUDHL8, and Farage & 66 \\
& GPR55 & Melanoma: A375 & 127 \\
& GPRI8 & Melanoma: A2058 & \\
& GPR55 & & 75 \\
& GPRII9 & & \\
Enzymes & $\uparrow$ FAAH & Non-small cell lung cancer: A459, A549, CALUI, H460, and HI299 & \\
& $\uparrow$ FAAH & Melanoma: A375 & \\
& $\downarrow$ NAPE-PLD & Glioma & \\
& $\downarrow$ MAGL & & 130 \\
& $\downarrow$ FAAH & & 138 \\
\hline FAAH & Prostate: LNCaP and DU-I45 \\
\hline
\end{tabular}

Notes: $\uparrow$, increased; $\downarrow$, decreased.

Abbreviations: HL, Hodgkin's lymphoma; NHL, non-Hodgkin's lymphoma.

positive correlation between $\mathrm{CB} 2$ expression and tumor malignancy. ${ }^{130} \mathrm{An}$ increased expression of $\mathrm{CB} 1$ and $\mathrm{CB} 2$ was observed in high-grade glioma (World Health Organization [WHO] grades III-IV) compared with lowgrade glioma (WHO grades I-II). ${ }^{130}$ With regard to ovarian cancer, immunohistochemical examination indicated that the expression of $\mathrm{CB} 1$ receptor was moderate in the benign and borderline epithelial tumors, while it was strong in the invasive tumors. ${ }^{131}$ It is quite an interesting observation since CB1 receptor (as well as FAAH) was found expressed in mouse ovarian surface epithelium, which is a major source of ovarian cancer. ${ }^{132}$ In human, CB1-IR was observed in ovarian cortex and medulla; however, the possibility of cannabinoid signaling contribution to ovarian carcinogenesis still exists and further investigation needs to be undertaken. ${ }^{133}$

In colon cancer, it has been shown that $\mathrm{CB} 2$ overexpression might be considered as a poor prognostic factor in patients with more advanced stage, involvement of lymph nodes, and vascular invasion. ${ }^{118}$ The authors pointed out that since patients in advanced stage of cancer are often submitted to adjuvant therapy, CB2 may be considered as a marker of treatment resistance. ${ }^{118}$ This notion may be supported by the fact that $\mathrm{CB} 2$ expression is correlated with the expression of SNAIL1, a transcription factor known for its role in mediating epithelial-mesenchymal transition (EMT). ${ }^{118,134}$ EMT is a process by which cancer cells acquire migratory properties and ability to metastasize to distant sites. ${ }^{135}$ The primary mechanism of SNAIL1-induced EMT is repression of epithelial markers, such as E-cadherin, and this effect promotes migratory, mesenchymal phenotype. ${ }^{134,135}$ It has been shown in several types of cancer that upregulation of SNAIL1 and further induction of EMT are associated with acquisition of radio- and chemoresistance. ${ }^{134-136}$ In colon cancer cells, a CB2 receptor agonist induced delocalization of E-cadherin from membrane to cytoplasm and increase in SNAIL1 expression. ${ }^{118}$ The changes that are related to the EMT process might explain the reason why treatment of patients in advanced stages who overexpress CB2 could be less effective.

Interesting findings were provided by Schley et a ${ }^{137}$ who reported abundant expression of CB2 in the endothelial cells of glioblastoma vessels. Given that active neovascularization is one of the most characteristic features of tumor invasion, the presence of $\mathrm{CB} 2$ in these areas may imply the possible exploitation of CB2 activation in cancer treatment. ${ }^{44,137}$ In fact, this assumption was further supported by the study in which two $\mathrm{CB} 2$ receptor agonists impaired growth of new skin tumor vessels. ${ }^{44}$

Recently, other components of the ECS in human neoplasms have drawn great attention. Androgen-dependent LNCaP cells exhibit a high level of FAAH mRNA and protein expression, and FAAH immunoreactivity has been subsequently shown to be inversely correlated with disease severity and outcome. ${ }^{138,139}$ A case was made that FAAH immunoreactivity is regulated by the local tumor microenvironment. It is supported by the facts that the IL-4 receptor was found on epithelial cells expressing FAAH and the incubation of prostate cells with this cytokine increased their FAAH activity. ${ }^{139}$ In fact, it was previously shown that lymphocyte treatment with IL-4 and IL-10 had a stimulating effect on FAAH, while incubation with IL-12 and IFN- $\gamma$ depressed the activity and lowered the expression of FAAH. ${ }^{140}$ It is already well known that progression of malignant disease is associated with Th1/Th2 cytokine imbalance and immune response polarization toward production of immunosuppressive IL-4, IL-10, and TGF- $\beta .{ }^{141,142}$ An increased expression of 
Th2 cytokines has been shown in tumor tissue and infiltrating lymphocytes in several cancer types such as renal cancer, pulmonary carcinoma, and glioma. ${ }^{141,142}$ In some of them, increased levels of IL-10 were considered as an unfavorable prognostic factor and were correlated with stage and histological grade. ${ }^{143,144}$ Accordingly, a gradual loss of Th1 population and an increase in Th2 may contribute to high FAAH expression level in cancer. These findings also raise the question whether upregulation of this molecule due to Th2-dominant cytokine profile is responsible for poor prognosis in cancer patients.

In glial malignancy, decreased expression and activity of NAPE-PLD and MAGL were found. ${ }^{130}$ Since NAPE-PLD and MAGL are the enzymes responsible for biosynthesis of anandamide and hydrolysis of 2-AG, respectively, their expression reflects the level of endogenous substrates in glioma tissues, namely, reduced level of anandamide and elevated level of 2-AG. However, with respect to FAAH, an anandamide-hydrolyzing enzyme, a significant downregulation was reported. It is plausible that in this case, the depression of FAAH might be a compensatory response to a low level of its substrate, therefore suggesting that MAGL has a greater influence on AEA level than FAAH. ${ }^{130}$

Although in most cases $\mathrm{CB} 1$ and $\mathrm{CB} 2$ are upregulated in cancer cells, there are reports indicating the opposite. Quantitative reverse transcription polymerase chain reaction and Western blot analyses revealed substantially reduced expression of $\mathrm{CB} 1$ receptor in colorectal carcinoma due to aberrant methylation within $\mathrm{CpG}$ islands of the $\mathrm{CB} 1$ promoter. ${ }^{119}$ This result may explain the general mechanism of $\mathrm{CB} 1$ expression loss, not only in colorectal cancer but also in all cancer types. Some interesting findings were demonstrated by Larrinaga et al ${ }^{116}$ who reported 12 -fold downregulation of CB1 mRNA, whereas immunohistochemical analysis revealed positive staining of this protein in chromophobe renal cell carcinoma. A previous study of this group provided contradictory results and showed presence of mRNA encoding CB1 in normal and tumor tissues of clear cell renal carcinoma, while Western blot and immunohistochemistry failed to demonstrate any content of CB1 protein. ${ }^{117}$ It indicates the importance of not relying only on mRNA levels when evaluating the expression of certain molecules, as mRNA expression may not reflect the protein status in the tissue due to modifications at the posttranscriptional level. ${ }^{117}$ A similar lack of correlation between mRNA and protein levels has been demonstrated in studies on other kidney diseases. ${ }^{145}$

Regarding the prognostic value, in pancreatic ductal adenocarcinoma, a low level of CB1 is related to better outcome, and this relationship is underlined by a significant correlation of high pain scores (18 out of 27 tissue specimens showing clinical pain demonstrated low receptor levels in nerves) with increased survival (median survival 11 months in low pain scores vs 24.5 months in high pain scores). ${ }^{146}$ This result may be explained by the fact that pain is a warning symptom of ongoing disease process and it contributes to earlier diagnosis and treatment initiation. ${ }^{146}$

An association of high expression of CB1 and CB2 receptors with poor prognosis in cancer patients is quite unexpected, considering the well-known antitumoral activity of CB ligands. A possible explanation for this ambiguity was given in a study on mouse astrocytoma cells. ${ }^{147}$ Cudaback et $\mathrm{al}^{147}$ showed that the level of $\mathrm{CB} 1$ and $\mathrm{CB} 2$ expression determines the efficacy of cannabinoids in cancer cells. It is suggested that the ECS mediates proapoptotic effects in cancer cells exhibiting low CB expression, while at high expression levels, it promotes cell survival due to activation of the Akt signaling pathway, known for its antiapoptotic effect. ${ }^{123,147}$ As summarized earlier, the ECS presents a heterogeneous pattern of expression in human cancers and this fact precludes its potential use as a prognostic marker in oncologic pathologies.

\section{Conclusion}

This review focused on current literature concerning ECS expression and the influence of its activation on cancer cell biology. As demonstrated earlier, CBs and other molecules closely related to ECS display a heterogeneous pattern of expression in human oncological pathologies, which probably impede its exploitation as prognostic markers in these diseases. Nevertheless, the fact that CB receptors are overexpressed in malignant cells compared to their nontransformed counterparts encouraged scientists to evaluate the influence of their ligands on several hallmarks of cancer. Indeed, synthetic and plant-derived cannabinoids, as well as endogenous compounds, exert a wide range of anticancer effects, including induction of autophagy and apoptosis, inhibition of proliferation, and reduction of metastasis outgrowth via antiangiogenic and antimigratory activities. They have also been found to stimulate immune response against cancer through enhanced recruitment of immune cells and, on the other hand, decreased migration of tumor-associated macrophages (particularly, protumorigenic M2 type) to the tumor microenvironment. Clearly, cannabinoids possess strong antiproliferative, proapoptotic, and antimetastatic properties, which have been confirmed in in vitro studies and in animal models. Despite a large amount of promising 
evidence for cannabinoid-induced antitumoral action, there is a lack of clinical research addressing this issue. Currently, cannabinoids are used clinically only in palliative therapy in cancer patients owing to antiemetic and analgesic properties of these compounds. The only clinical trial undertaken so far concerned patients with recurrent glioblastoma multiforme. ${ }^{148}$ In this study, intracranial delivery of $\Delta^{9}$-THC displayed a fair drug safety profile and did not induce overt psychoactive side effects. ${ }^{148}$ Therefore, future research should be directed toward possible application of these compounds in therapy, at least as adjunctive treatment. In particular, combination therapy utilizing cannabinoids and conventional treatments may be a beneficial option for patients who do not respond to common therapies.

\section{Acknowledgment}

The study was performed within the project "Centre for Innovative Research in Medical and Natural Sciences", realized by the University of Rzeszów, cofinanced within "Regional Operational Programme for the Podkarpackie Province" for the years 2007-2013, contract number UDARPPK.01.03.00-18-004/12-00.

\section{Disclosure}

The authors report no conflicts of interest in this work.

\section{References}

1. Pisanti S, Picardi P, D’Alessandro A, Laezza C, Bifulco M. The endocannabinoid signaling system in cancer. Trends Pharmacol Sci. 2013;34:273-282.

2. Devane WA, Dysarz FA, Johnson MR, Melvin LS, Howlett AC. Determination and characterization of a cannabinoid receptor in rat brain. Mol Pharmacol. 1988;34(5):605-613.

3. Munro S, Thomas KL, Abu-Shaar M. Molecular characterization of a peripheral receptor for cannabinoids. Nature. 1993;365(6441):61-65.

4. Sharir H, Abood ME. Pharmacological characterization of GPR55, a putative cannabinoid receptor. Pharmacol Ther. 2010;126(3): 301-313.

5. Guzmán M. Cannabinoids: potential anticancer agents. Nat Rev Cancer. 2003;3(10):745-755.

6. Pisanti S, Malfitano AM, Grimaldi C, et al. Use of cannabinoid receptor agonists in cancer therapy as palliative and curative agents. Best Pract Res Clin Endocrinol Metab. 2009;23(1):117-131.

7. Fonseca BM, Teixeira NA, Almada M, Taylor AH, Konje JC, Correiada-Silva G. Modulation of the novel cannabinoid receptor - GPR55 during rat fetoplacental development. Placenta. 2011;32(6):462-469.

8. Henstridge CM, Balenga NA, Schröder R, et al. GPR55 ligands promote receptor coupling to multiple signalling pathways. Br J Pharmacol. 2010;160(3):604-614.

9. Godlewski G, Offertáler L, Wagner JA, Kunos G. Receptors for acylethanolamides-GPR55 and GPR119. Prostaglandins Other Lipid Mediat. 2009;89(3-4):105-111.

10. Sawzdargo M, George SR, Nguyen T, Xu S, Kolakowski LF, O’DowdBF. A cluster of four novel human $\mathrm{G}$ protein-coupled receptor genes occurring in close proximity to CD22 gene on chromosome 19q13.1. Biochem Biophys Res Commun. 1997;239(2):543-547.
11. Waldeck-Weiermair M, Zoratti C, Osibow $\mathrm{K}$, et al. Integrin clustering enables anandamide-induced $\mathrm{Ca} 2+$ signaling in endothelial cells via GPR55 by protection against CB1-receptor-triggered repression. J Cell Sci. 2008;121(pt 10):1704-1717.

12. Bifulco M, Laezza C, Pisanti S, Gazzerro P. Cannabinoids and cancer: pros and cons of an antitumour strategy. Br J Pharmacol. 2006;148(2): 123-135.

13. Pertwee RG. Pharmacological actions of cannabinoids. Handb Exp Pharmacol. 2005;(168):1-51.

14. De Petrocellis L, Di Marzo V. An introduction to the endocannabinoid system: from the early to the latest concepts. Best Pract Res Clin Endocrinol Metab. 2009;23(1):1-15.

15. Ulugöl A. The endocannabinoid system as a potential therapeutic target for pain modulation. Balk Med J. 2014;31:115-120.

16. Pertwee RG. Ligands that target cannabinoid receptors in the brain: from THC to anandamide and beyond. Addict Biol. 2008;13(2):147-159.

17. Kano M. Control of synaptic function by endocannabinoid-mediated retrograde signaling. Proc Jpn Acad Ser B Phys Biol Sci. 2014;90(7): 235-250.

18. Ayakannu T, Taylor AH, Marczylo TH, Willets JM, Konje JC. The endocannabinoid system and sex steroid hormone-dependent cancers. Int $J$ Endocrinol. 2013;2013:259676.

19. Guindon J, Hohmann AG. The endocannabinoid system and cancer: therapeutic implication. Br J Pharmacol. 2011;163(7):1447-1463.

20. Muccioli GG. Endocannabinoid biosynthesis and inactivation, from simple to complex. Drug Discov Today. 2010;15(11-12):474-483.

21. Contassot E, Tenan M, Schnüriger V, Pelte M-F, Dietrich P-Y. Arachidonyl ethanolamide induces apoptosis of uterine cervix cancer cells via aberrantly expressed vanilloid receptor-1. Gynecol Oncol. 2004;93(1):182-188.

22. Ruhaak LR, Felth J, Karlsson PC, Rafter JJ, Verpoorte R, Bohlin L. Evaluation of the cyclooxygenase inhibiting effects of six major cannabinoids isolated from Cannabis sativa. Biol Pharm Bull. 2011; 34(5):774-778.

23. Vara D, Morell C, Rodríguez-Henche N, Diaz-Laviada I. Involvement of PPAR $\gamma$ in the antitumoral action of cannabinoids on hepatocellular carcinoma. Cell Death Dis. 2013;4:e618.

24. Sánchez C, Galve-Roperh I, Rueda D, Guzmán M. Involvement of sphingomyelin hydrolysis and the mitogen-activated protein kinase cascade in the Delta9-tetrahydrocannabinol-induced stimulation of glucose metabolism in primary astrocytes. Mol Pharmacol. 1998;54(5):834-843.

25. Galve-Roperh I, Sánchez C, Cortés ML, Gómez del Pulgar T, Izquierdo M, Guzmán M. Anti-tumoral action of cannabinoids: involvement of sustained ceramide accumulation and extracellular signal-regulated kinase activation. Nat Med. 2000;6(3):313-319.

26. Melck D, Rueda D, Galve-Roperh I, De Petrocellis L, Guzmán M, Di Marzo V. Involvement of the cAMP/protein kinase A pathway and of mitogen-activated protein kinase in the anti-proliferative effects of anandamide in human breast cancer cells. FEBS Lett. 1999;463(3):235-240.

27. Mimeault M, Pommery N, Wattez N, Bailly C, Hénichart J-P. Antiproliferative and apoptotic effects of anandamide in human prostatic cancer cell lines: implication of epidermal growth factor receptor down-regulation and ceramide production. Prostate. 2003;56(1): $1-12$.

28. Nithipatikom K, Gomez-Granados AD, Tang AT, Pfeiffer AW, Williams CL, Campbell WB. Cannabinoid receptor type 1 (CB1) activation inhibits small GTPase RhoA activity and regulates motility of prostate carcinoma cells. Endocrinology. 2012;153(1):29-41.

29. Oesch S, Gertsch J. Cannabinoid receptor ligands as potential anticancer agents - high hopes for new therapies? J Pharm Pharmacol. 2009;61(7):839-853.

30. Rueda D, Galve-Roperh I, Haro A, Guzmán M. The CB(1) cannabinoid receptor is coupled to the activation of c-Jun N-terminal kinase. $\mathrm{Mol}$ Pharmacol. 2000;58(4):814-820. 
31. Fonseca BM, Correia-da-Silva G, Teixeira NA. The endocannabinoid anandamide induces apoptosis of rat decidual cells through a mechanism involving ceramide synthesis and p38 MAPK activation. Apoptosis. 2013;18(12):1526-1535.

32. Gómez del Pulgar T, Velasco G, Sánchez C, Haro A, Guzmán M. De novo-synthesized ceramide is involved in cannabinoid-induced apoptosis. Biochem J. 2002;363(pt 1):183-188.

33. Hsu S-S, Huang C-J, Cheng H-H, et al. Anandamide-induced Ca2+ elevation leading to $\mathrm{p} 38$ MAPK phosphorylation and subsequent cell death via apoptosis in human osteosarcoma cells. Toxicology. 2007; 231(1):21-29.

34. Blázquez C, Salazar M, Carracedo A, et al. Cannabinoids inhibit glioma cell invasion by down-regulating matrix metalloproteinase- 2 expression. Cancer Res. 2008;68(6):1945-1952.

35. Blázquez C, Galve-Roperh I, Guzmán M. De novo-synthesized ceramide signals apoptosis in astrocytes via extracellular signal-regulated kinase. FASEB J. 2000;14(14):2315-2322.

36. Sarfaraz S, Afaq F, Adhami VM, Malik A, Mukhtar H. Cannabinoid receptor agonist-induced apoptosis of human prostate cancer cells LNCaP proceeds through sustained activation of ERK1/2 leading to G1 cell cycle arrest. J Biol Chem. 2006;281(51):39480-39491.

37. Xian X-S, Park H, Choi M-G, Park JM. Cannabinoid receptor agonist as an alternative drug in 5-fluorouracil-resistant gastric cancer cells. Anticancer Res. 2013;33(6):2541-2547.

38. Chakravarti B, Ravi J, Ganju RK. Cannabinoids as therapeutic agents in cancer: current status and future implications. Oncotarget. 2014; 5(15):5852-5872.

39. Pacher P, Bátkai S, Kunos G. The endocannabinoid system as an emerging target of pharmacotherapy. Pharmacol Rev. 2006;58(3):389-462.

40. Chung SC, Hammarsten P, Josefsson A, et al. A high cannabinoid $\mathrm{CB}(1)$ receptor immunoreactivity is associated with disease severity and outcome in prostate cancer. Eur J Cancer. 2009;45(1):174-182.

41. Munson AE, Harris LS, Friedman MA, Dewey WL, Carchman RA. Antineoplastic activity of cannabinoids. J Natl Cancer Inst. 1975;55(3): 597-602.

42. Aviello G, Romano B, Borrelli F, et al. Chemopreventive effect of the non-psychotropic phytocannabinoid cannabidiol on experimental colon cancer. J Mol Med (Berl). 2012;90(8):925-934.

43. Blázquez C, González-Feria L, Alvarez L, Haro A, Casanova ML, Guzmán M. Cannabinoids inhibit the vascular endothelial growth factor pathway in gliomas. Cancer Res. 2004;64(16):5617-5623.

44. Casanova ML, Blázquez C, Martínez-Palacio J, et al. Inhibition of skin tumor growth and angiogenesis in vivo by activation of cannabinoid receptors. J Clin Invest. 2003;111(1):43-50.

45. Dando I, Donadelli M, Costanzo C, et al. Cannabinoids inhibit energetic metabolism and induce AMPK-dependent autophagy in pancreatic cancer cells. Cell Death Dis. 2013;4:e664.

46. Donadelli M, Dando I, Zaniboni T, et al. Gemcitabine/cannabinoid combination triggers autophagy in pancreatic cancer cells through a ROS-mediated mechanism. Cell Death Dis. 2011;2:e152.

47. Elbaz M, Nasser MW, Ravi J, et al. Modulation of the tumor microenvironment and inhibition of EGF/EGFR pathway: novel anti-tumor mechanisms of cannabidiol in breast cancer. Mol Oncol. 2015;9(4): 906-919.

48. Gasperi V, Evangelista D, Oddi S, et al. Regulation of inflammation and proliferation of human bladder carcinoma cells by type-1 and type- 2 cannabinoid receptors. Life Sci. 2015;138:41-51.

49. Park JM, Xian X-S, Choi M-G, et al. Antiproliferative mechanism of a cannabinoid agonist by cell cycle arrest in human gastric cancer cells. J Cell Biochem. 2011;112(4):1192-1205.

50. Pellerito O, Notaro A, Sabella S, et al. WIN induces apoptotic cell death in human colon cancer cells through a block of autophagic flux dependent on PPAR $\gamma$ down-regulation. Apoptosis. 2014;19(6): 1029-1042.

51. Salazar M, Carracedo A, Salanueva ÍJ, et al. Cannabinoid action induces autophagy-mediated cell death through stimulation of ER stress in human glioma cells. J Clin Invest. 2009;119(5):1359-1372.
52. Soliman E, Henderson KL, Danell AS, Van Dross R. Arachidonoylethanolamide activates endoplasmic reticulum stress-apoptosis in tumorigenic keratinocytes: role of cyclooxygenase- 2 and novel J-series prostamides. Mol Carcinog. 2016;55(2):117-130.

53. Xian X-S, Park H, Cho YK, et al. Effect of a synthetic cannabinoid agonist on the proliferation and invasion of gastric cancer cells. $J$ Cell Biochem. 2010;110(2):321-332.

54. Raiter A, Yerushalmi R, Hardy B. Pharmacological induction of cell surface GRP78 contributes to apoptosis in triple negative breast cancer cells. Oncotarget. 2014;5(22):11452-11463.

55. Sanchez-Lopez E, Zimmerman T, Gomez del Pulgar T, Moyer MP, Lacal Sanjuan JC, Cebrian A. Choline kinase inhibition induces exacerbated endoplasmic reticulum stress and triggers apoptosis via CHOP in cancer cells. Cell Death Dis. 2013;4:e933.

56. Zheng Y-Z, Cao Z-G, Hu X, Shao Z-M. The endoplasmic reticulum stress markers GRP78 and CHOP predict disease-free survival and responsiveness to chemotherapy in breast cancer. Breast Cancer Res Treat. 2014;145(2):349-358.

57. Yu X, Lv J, Zhu Y, Duan L, Ma L. Homocysteine inhibits hepatocyte proliferation via endoplasmic reticulum stress. PLoS One. 2013;8(1):e54265.

58. Carracedo A, Lorente M, Egia A, et al. The stress-regulated protein $\mathrm{p} 8$ mediates cannabinoid-induced apoptosis of tumor cells. Cancer Cell. 2006;9(4):301-312.

59. Notaro A, Sabella S, Pellerito O, et al. Involvement of PAR-4 in cannabinoid-dependent sensitization of osteosarcoma cells to TRAILinduced apoptosis. Int J Biol Sci. 2014;10(5):466-478.

60. Hong Y, Zhou Y, Wang Y, Xiao S, Liao DJ, Zhao Q. PPAR $\gamma$ mediates the effects of WIN55,212-2, an synthetic cannabinoid, on the proliferation and apoptosis of the BEL-7402 hepatocarcinoma cells. Mol Biol Rep. 2013;40(11):6287-6293.

61. Ramer R, Heinemann K, Merkord J, et al. COX-2 and PPAR- $\gamma$ confer cannabidiol-induced apoptosis of human lung cancer cells. Mol Cancer Ther. 2013;12(1):69-82.

62. De Petrocellis L, Ligresti A, Schiano Moriello A, et al. Non-THC cannabinoids inhibit prostate carcinoma growth in vitro and in vivo: pro-apoptotic effects and underlying mechanisms. Br J Pharmacol. 2013;168(1):79-102.

63. Romano B, Borrelli F, Pagano E, Cascio MG, Pertwee RG, Izzo AA. Inhibition of colon carcinogenesis by a standardized Cannabis sativa extract with high content of cannabidiol. Phytomedicine. 2014;21(5): 631-639.

64. Ortega A, Rangel-López E, Hidalgo-Miranda A, et al. On the effects of CP 55-940 and other cannabinoid receptor agonists in C6 and U373 cell lines. Toxicol In Vitro. 2015;29(7):1941-1951.

65. Kargl J, Haybaeck J, Stančić A, et al. O-1602, an atypical cannabinoid, inhibits tumor growth in colitis-associated colon cancer through multiple mechanisms. J Mol Med (Berl). 2013;91(4):449-458.

66. Adinolfi B, Romanini A, Vanni A, et al. Anticancer activity of anandamide in human cutaneous melanoma cells. Eur J Pharmacol. 2013; 718(1-3):154-159.

67. Xia P, Zhang R, Ge G. C/EBP $\beta$ mediates TNF- $\alpha$-induced cancer cell migration by inducing MMP expression dependent on p38 MAPK. J Cell Biochem. 2015;116(12):2766-2777.

68. Emery SM, Alotaibi MR, Tao Q, Selley DE, Lichtman AH, Gewirtz DA. Combined antiproliferative effects of the aminoalkylindole WIN55,212-2 and radiation in breast cancer cells. J Pharmacol Exp Ther. 2014;348(2):293-302.

69. Hirsch FR, Varella-Garcia M, Cappuzzo F. Predictive value of EGFR and HER2 overexpression in advanced non-small-cell lung cancer. Oncogene. 2009;28(suppl 1):S32-S37.

70. Hu T, Li C. Convergence between Wnt- $\beta$-catenin and EGFR signaling in cancer. Mol Cancer. 2010;9:236.

71. Tomas A, Futter CE, Eden ER. EGF receptor trafficking: consequences for signaling and cancer. Trends Cell Biol. 2014;24(1):26-34.

72. Jørgensen JT. Role of human epidermal growth factor receptor 2 in gastric cancer: biological and pharmacological aspects. World $J$ Gastroenterol. 2014;20(16):4526-4535. 
73. Fowler CJ, Hammarsten P, Bergh A. Tumour cannabinoid CB(1) receptor and phosphorylated epidermal growth factor receptor expression are additive prognostic markers for prostate cancer. PLoS One. 2010; 5(12):e15205.

74. Fiori JL, Sanghvi M, O’Connell MP, Krzysik-Walker SM, Moaddel R, Bernier M. The cannabinoid receptor inverse agonist AM251 regulates the expression of the EGF receptor and its ligands via destabilization of oestrogen-related receptor $\alpha$ protein. Br J Pharmacol. 2011; 164(3):1026-1040.

75. Ravi J, Sneh A, Shilo K, Nasser MW, Ganju RK. FAAH inhibition enhances anandamide mediated anti-tumorigenic effects in nonsmall cell lung cancer by downregulating the EGF/EGFR pathway. Oncotarget. 2014;5(9):2475-2486.

76. Cipriano M, Gouveia-Figueira S, Persson E, Nording M, Fowler CJ. The influence of monoacylglycerol lipase inhibition upon the expression of epidermal growth factor receptor in human PC-3 prostate cancer cells. BMC Res Notes. 2014;7:441.

77. Levine B, Kroemer G. Autophagy in the pathogenesis of disease. Cell. 2008;132(1):27-42.

78. Maycotte P, Thorburn A. Autophagy and cancer therapy. Cancer Biol Ther. 2011;11:127-137.

79. Donadelli M, Costanzo C, Beghelli S, et al. Synergistic inhibition of pancreatic adenocarcinoma cell growth by trichostatin A and gemcitabine. Biochim Biophys Acta. 2007;1773(7):1095-1106.

80. Vara D, Salazar M, Olea-Herrero N, Guzmán M, Velasco G, DíazLaviada I. Anti-tumoral action of cannabinoids on hepatocellular carcinoma: role of AMPK-dependent activation of autophagy. Cell Death Differ. 2011;18(7):1099-1111.

81. Wang F, Cho WCS, Chan LW, et al. Gene network exploration of crosstalk between apoptosis and autophagy in chronic myelogenous leukemia. Biomed Res Int. 2015;2015:459840.

82. Mariño G, Niso-Santano M, Baehrecke EH, Kroemer G. Selfconsumption: the interplay of autophagy and apoptosis. Nat Rev Mol Cell Biol. 2014;15(2):81-94

83. Schröder M, Kaufman RJ. The mammalian unfolded protein response. Annu Rev Biochem. 2005;74:739-789.

84. Murase R, Kawamura R, Singer E, et al. Targeting multiple cannabinoid anti-tumour pathways with a resorcinol derivative leads to inhibition of advanced stages of breast cancer. Br J Pharmacol. 2014;171(19): 4464-4477.

85. Armstrong JL, Hill DS, McKee CS, et al. Exploiting cannabinoidinduced cytotoxic autophagy to drive melanoma cell death. $J$ Invest Dermatol. 2015;135(6):1629-1637.

86. Shay G, Lynch CC, Fingleton B. Moving targets: emerging roles for MMPs in cancer progression and metastasis. Matrix Biol. 2015; 4(4-46):200-206.

87. Kessenbrock K, Wang C-Y, Werb Z. Matrix metalloproteinases in stem cell regulation and cancer. Matrix Biol. 2015;4(4-46):184-190.

88. Li C-Y, Yuan P, Lin S-S, et al. Matrix metalloproteinase 9 expression and prognosis in colorectal cancer: a meta-analysis. Tumour Biol. 2013; 34(2):735-741.

89. Peng H, Liu L, Zhao X. Prognostic significance of matrix metalloproteinase-2 in gynecological cancer: a systemic review of the literature and meta-analysis. J BUON. 2013;18(1):202-210.

90. Song J, Su H, Zhou Y-Y, Guo L-L. Prognostic value of matrix metalloproteinase 9 expression in breast cancer patients: a meta-analysis. Asian Pac J Cancer Prev. 2013;14(3):1615-1621.

91. Sun D, Zhang Y, Qi Y, Zhou X, Lv G. Prognostic significance of MMP-7 expression in colorectal cancer: a meta-analysis. Cancer Epidemiol. 2015;39(2):135-142.

92. Caballero FJ, Soler-Torronteras R, Lara-Chica M, et al. AM404 inhibits NFAT and NF- $\mathrm{KB}$ signaling pathways and impairs migration and invasiveness of neuroblastoma cells. Eur J Pharmacol. 2015;746: 221-232.

93. Pisanti S, Borselli C, Oliviero O, Laezza C, Gazzerro P, Bifulco M. Antiangiogenic activity of the endocannabinoid anandamide: correlation to its tumor-suppressor efficacy. J Cell Physiol. 2007;211(2):495-503.
94. Solinas M, Massi P, Cantelmo AR, et al. Cannabidiol inhibits angiogenesis by multiple mechanisms. Br J Pharmacol. 2012;167(6):1218-1231.

95. Groblewska M, Siewko M, Mroczko B, Szmitkowski M. The role of matrix metalloproteinases (MMPs) and their inhibitors (TIMPs) in the development of esophageal cancer. Folia Histochem Cytobiol. 2012;50(1):12-19.

96. Ramer R, Fischer S, Haustein M, Manda K, Hinz B. Cannabinoids inhibit angiogenic capacities of endothelial cells via release of tissue inhibitor of matrix metalloproteinases-1 from lung cancer cells. Biochem Pharmacol. 2014;91(2):202-216.

97. Ramer R, Bublitz K, Freimuth N, et al. Cannabidiol inhibits lung cancer cell invasion and metastasis via intercellular adhesion molecule-1. FASEB J. 2012;26(4):1535-1548.

98. Ramer R, Hinz B. Inhibition of cancer cell invasion by cannabinoids via increased expression of tissue inhibitor of matrix metalloproteinases- 1 . J Natl Cancer Inst. 2008;100(1):59-69.

99. Fujihara T, Yashiro M, Inoue T, et al. Decrease in ICAM-1 expression on gastric cancer cells is correlated with lymph node metastasis. Gastric Cancer. 1999;2(4):221-225.

100. Maeda K, Kang S-M, Sawada T, et al. Expression of intercellular adhesion molecule-1 and prognosis in colorectal cancer. Oncol Rep. 2002; 9(3):511-514.

101. Sartor WM, Kyprianou N, Fabian DF, Lefor AT. Enhanced expression of ICAM-1 in a murine fibrosarcoma reduces tumor growth rate. J Surg Res. 1995;59(1):66-74.

102. Haustein M, Ramer R, Linnebacher M, Manda K, Hinz B. Cannabinoids increase lung cancer cell lysis by lymphokine-activated killer cells via upregulation of ICAM-1. Biochem Pharmacol. 2014;92(2): $312-325$

103. Gasperi V, Evangelista D, Chiurchiù V, et al. 2-Arachidonoylglycerol modulates human endothelial cell/leukocyte interactions by controlling selectin expression through $\mathrm{CB} 1$ and $\mathrm{CB} 2$ receptors. Int J Biochem Cell Biol. 2014;51:79-88.

104. Soroceanu L, Murase R, Limbad C, et al. Id-1 is a key transcriptional regulator of glioblastoma aggressiveness and a novel therapeutic target. Cancer Res. 2013;73(5):1559-1569.

105. Gumireddy K, Li A, Kossenkov AV, et al. ID1 promotes breast cancer metastasis by S100A9 regulation. Mol Cancer Res. 2014;12(9): 1334-1343.

106. Patel D, Morton DJ, Carey J, Havrda MC, Chaudhary J. Inhibitor of differentiation 4 (ID4): from development to cancer. Biochim Biophys Acta. 2015;1855(1):92-103.

107. Cao Z, Shang B, Zhang G, et al. Tumor cell-mediated neovascularization and lymphangiogenesis contrive tumor progression and cancer metastasis. Biochim Biophys Acta. 2013;1836(2):273-286.

108. Carmeliet P, Jain RK. Molecular mechanisms and clinical applications of angiogenesis. Nature. 2011;473:298-307.

109. Shibuya M. Differential roles of vascular endothelial growth factor receptor-1 and receptor-2 in angiogenesis. J Biochem Mol Biol. 2006; 39(5):469-478

110. Hofmann NA, Barth S, Waldeck-Weiermair M, et al. TRPV1 mediates cellular uptake of anandamide and thus promotes endothelial cell proliferation and network-formation. Biol Open. 2014;3(12):1164-1172.

111. Hsu C-J, Wu M-H, Chen C-Y, Tsai C-H, Hsu H-C, Tang C-H. AMP-activated protein kinase activation mediates CCL3-induced cell migration and matrix metalloproteinase-2 expression in human chondrosarcoma. Cell Commun Signal. 2013;11:68.

112. Su S, Liu Q, Chen J, et al. A positive feedback loop between mesenchymal-like cancer cells and macrophages is essential to breast cancer metastasis. Cancer Cell. 2014;25(5):605-620.

113. Wu Y, Li Y-Y, Matsushima K, Baba T, Mukaida N. CCL3-CCR5 axis regulates intratumoral accumulation of leukocytes and fibroblasts and promotes angiogenesis in murine lung metastasis process. J Immunol. 2008;181(9):6384-6393.

114. Sarfaraz S, Afaq F, Adhami VM, Mukhtar H. Cannabinoid receptor as a novel target for the treatment of prostate cancer. Cancer Res. 2005; 65(5):1635-1641. 
115. Xu X, Liu Y, Huang S, et al. Overexpression of cannabinoid receptors CB1 and CB2 correlates with improved prognosis of patients with hepatocellular carcinoma. Cancer Genet Cytogenet. 2006;171(1): 31-38.

116. Larrinaga G, Sanz B, Blanco L, et al. Cannabinoid CB1 receptor is expressed in chromophobe renal cell carcinoma and renal oncocytoma. Clin Biochem. 2013;46(7-8):638-641.

117. Larrinaga G, Sanz B, Pérez I, et al. Cannabinoid CB1 receptor is downregulated in clear cell renal cell carcinoma. J Histochem Cytochem. 2010;58:1129-1134.

118. Martínez-Martínez E, Gómez I, Martín P, et al. Cannabinoids receptor type 2, CB2, expression correlates with human colon cancer progression and predicts patient survival. Oncoscience. 2015;2(2): $131-141$

119. Wang D, Wang H, Ning W, Backlund MG, Dey SK, DuBois RN. Loss of cannabinoid receptor 1 accelerates intestinal tumor growth. Cancer Res. 2008;68(15):6468-6476.

120. Sánchez C, de Ceballos ML, Gomez del Pulgar T, et al. Inhibition of glioma growth in vivo by selective activation of the $\mathrm{CB}(2)$ cannabinoid receptor. Cancer Res. 2001;61(15):5784-5789.

121. Ellert-Miklaszewska A, Grajkowska W, Gabrusiewicz K, Kaminska B, Konarska L. Distinctive pattern of cannabinoid receptor type II (CB2) expression in adult and pediatric brain tumors. Brain Res. 2007; 1137(1):161-169.

122. De Jesús ML, Hostalot C, Garibi JM, Sallés J, Meana JJ, Callado LF. Opposite changes in cannabinoid $\mathrm{CB} 1$ and $\mathrm{CB} 2$ receptor expression in human gliomas. Neurochem Int. 2010;56(6-7):829-833.

123. Cipriano M, Häggström J, Hammarsten P, Fowler CJ. Association between cannabinoid $\mathrm{CB}_{1}$ receptor expression and Akt signalling in prostate cancer. PLoS One. 2013;8:e65798.

124. Gustafsson SB, Palmqvist R, Henriksson ML, et al. High tumour cannabinoid $\mathrm{CB} 1$ receptor immunoreactivity negatively impacts disease-specific survival in stage II microsatellite stable colorectal cancer. PLoS One. 2011;6(8):e23003.

125. Jung CK, Kang WK, Park JM, et al. Expression of the cannabinoid type I receptor and prognosis following surgery in colorectal cancer. Oncol Lett. 2013;5(3):870-876.

126. Benz AH, Renné C, Maronde E, et al. Expression and functional relevance of cannabinoid receptor 1 in Hodgkin lymphoma. PLoS One. 2013;8(12):e81675.

127. Haskó J, Fazakas C, Molnár J, et al. CB2 receptor activation inhibits melanoma cell transmigration through the blood-brain barrier. Int $J$ Mol Sci. 2014;15(5):8063-8074.

128. Klein Nulent TJW, Van Diest PJ, van der Groep P, et al. Cannabinoid receptor-2 immunoreactivity is associated with survival in squamous cell carcinoma of the head and neck. Br J Oral Maxillofac Surg. 2013; 51(7):604-609.

129. Zhu LX, Sharma S, Stolina M, et al. Delta-9-tetrahydrocannabinol inhibits antitumor immunity by a CB2 receptor-mediated, cytokinedependent pathway. J Immunol. 2000;165(1):373-380.

130. Wu X, Han L, Zhang X, et al. Alteration of endocannabinoid system in human gliomas. J Neurochem. 2012;120(5):842-849.

131. Messalli EM, Grauso F, Luise R, Angelini A, Rossiello R. Cannabinoid receptor type 1 immunoreactivity and disease severity in human epithelial ovarian tumors. Am J Obstet Gynecol. 2014;211(3): 234.e1-234.e6.

OncoTargets and Therapy

\section{Publish your work in this journal}

OncoTargets and Therapy is an international, peer-reviewed, open access journal focusing on the pathological basis of all cancers, potential targets for therapy and treatment protocols employed to improve the management of cancer patients. The journal also focuses on the impact of management programs and new therapeutic agents and protocols on
132. Bagavandoss $P$, Grimshaw $S$. Temporal and spatial distribution of the cannabinoid receptors (CB1, CB2) and fatty acid amide hydroxylase in the rat ovary. Anat Rec (Hoboken). 2010;293(8):1425-1432.

133. El-Talatini MR, Taylor AH, Elson JC, Brown L, Davidson AC, Konje JC. Localisation and function of the endocannabinoid system in the human ovary. PLoS One. 2009;4(2):e4579.

134. Kaufhold S, Bonavida B. Central role of Snail1 in the regulation of EMT and resistance in cancer: a target for therapeutic intervention. $J$ Exp Clin Cancer Res. 2014;33:62.

135. Fan F, Samuel S, Evans KW, et al. Overexpression of Snail induces epithelial-mesenchymal transition and a cancer stem cell-like phenotype in human colorectal cancer cells. Cancer Med. 2012;1: 5-16.

136. Kurrey NK, Jalgaonkar SP, Joglekar AV, et al. Snail and slug mediate radioresistance and chemoresistance by antagonizing p53-mediated apoptosis and acquiring a stem-like phenotype in ovarian cancer cells. Stem Cells. 2009;27(9):2059-2068.

137. Schley M, Ständer S, Kerner J, et al. Predominant CB2 receptor expression in endothelial cells of glioblastoma in humans. Brain Res Bull. 2009;79(5):333-337.

138. Endsley MP, Thill R, Choudhry I, et al. Expression and function of fatty acid amide hydrolase in prostate cancer. Int $J$ Cancer. 2008;123(6):1318-1326.

139. Thors L, Bergh A, Persson E, et al. Fatty acid amide hydrolase in prostate cancer: association with disease severity and outcome, CB1 receptor expression and regulation by IL-4. PLoS One. 2010;5(8): e12275.

140. Maccarrone M, Valensise H, Bari M, Lazzarin N, Romanini C, Finazzi-Agrò A. Progesterone up-regulates anandamide hydrolase in human lymphocytes: role of cytokines and implications for fertility. J Immunol. 2001;166(12):7183-7189.

141. Chechlińska M. Rola cytokin w procesach nowotworzenia [The role of cytokines in carcinogenesis]. J Oncol. 2003;53:648-659.

142. Kicielińska J, Pajtasz-Piasecka E. Rola IL-10 w modulowaniu odpowiedzi odpornościowej w warunkach prawidłowych oraz w środowisku nowotworu. Role IL-10 [The role of IL-10 in the modulation of the immune response in normal conditions and the tumor environment]. Postepy Hig Med Dosw. 2014;68:879-892.

143. Becker Y. Molecular immunological approaches to biotherapy of human cancers - a review, hypothesis and implications. Anticancer Res. 2006;26(2A):1113-1134.

144. Chang W-J, Du Y, Zhao X, Ma L-Y, Cao G-W. Inflammation-related factors predicting prognosis of gastric cancer. World J Gastroenterol. 2014;20(16):4586-4596.

145. Kasinath BS, Mariappan MM, Sataranatarajan K, Lee MJ, Feliers D. mRNA translation: unexplored territory in renal science. J Am Soc Nephrol. 2006;17(12):3281-3292.

146. Michalski CW, Oti FE, Erkan M, et al. Cannabinoids in pancreatic cancer: correlation with survival and pain. Int J Cancer. 2008;122(4): $742-750$.

147. Cudaback E, Marrs W, Moeller T, Stella N. The expression level of $\mathrm{CB} 1$ and $\mathrm{CB} 2$ receptors determines their efficacy at inducing apoptosis in astrocytomas. PLoS One. 2010;5(1):e8702.

148. Guzmán M, Duarte MJ, Blázquez C, et al. A pilot clinical study of Delta9-tetrahydrocannabinol in patients with recurrent glioblastoma multiforme. Br J Cancer. 2006;95(2):197-203.

\section{Dovepress}

patient perspectives such as quality of life, adherence and satisfaction The manuscript management system is completely online and includes a very quick and fair peer-review system, which is all easy to use. Visit http://www.dovepress.com/testimonials.php to read real quotes from published authors. 